\title{
Comparative functional dynamics studies on the enzyme nano-bio interface
}

This article was published in the following Dove Press journal:

International Journal of Nanomedicine

Spencer E Thomas, ${ }^{1,2, *}$ Jeffrey Comer, ',* Min Jung Kim,' Shanna Marroquin,' Vaibhav Murthy, 'Meghana Ramani,' Tabetha Gaile Hopke, ${ }^{2}$ Jayden McCall,' Seong-O Choi,' Robert K DeLong'

'Nanotechnology Innovation Center of Kansas State, Department of Anatomy and Physiology, College of Veterinary Medicine, Kansas State University, Manhattan, KS, USA; ${ }^{2}$ Department of Biomedical Science, Missouri State University, Springfield, MO, USA

*These authors contributed equally to this work

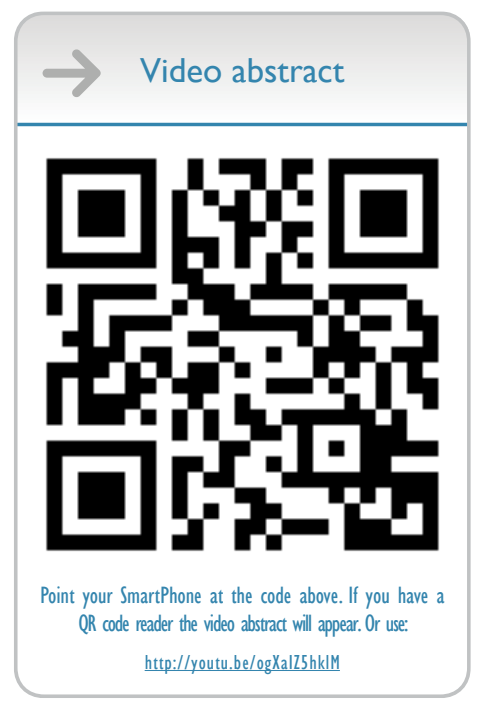

Correspondence: Robert K DeLong Nanotechnology Innovation Center Kansas State, Department of Anatomy and Physiology, College of Veterinary Medicine, Kansas State University, Mosier Hall P200, 1800 Denison

Ave., Manhattan, KS 66502, USA

Tel + I 7855326313

Email robertdelong@vet.k-state.edu
Introduction: Biomedical applications of nanoparticles (NPs) as enzyme inhibitors have recently come to light. Oxides of metals native to the physiological environment (eg, $\mathrm{Fe}, \mathrm{Zn}, \mathrm{Mg}$, etc.) are of particular interest - especially the functional consequences of their enzyme interaction. Materials and methods: Here, $\mathrm{Fe}_{2} \mathrm{O}_{3}$, zinc oxide $(\mathrm{ZnO})$, magnesium oxide $(\mathrm{MgO})$ and nickel oxide $(\mathrm{NiO}) \mathrm{NPs}$ are compared to copper $(\mathrm{Cu})$ and boron carbide $\left(\mathrm{B}_{4} \mathrm{C}\right) \mathrm{NPs}$. The functional impact of NP interaction to the model enzyme luciferase is determined by 2-dimensional fluorescence difference spectroscopy (2-D FDS) and 2-dimensional photoluminescence difference spectroscopy (2-D PLDS). By 2-D FDS analysis, the change in maximal intensity and in 2-D FDS area under the curve (AUC) is in the order $\mathrm{Cu} \sim \mathrm{B}_{4} \mathrm{C}>\mathrm{ZnO}>\mathrm{NiO}>>\mathrm{Fe}_{2} \mathrm{O}_{3}>\mathrm{MgO}$. The induced changes in protein conformation are confirmed by tryptic digests and gel electrophoresis.

Results: Analysis of possible trypsin cleavage sites suggest that cleavage mostly occurs in the range of residues 112-155 and 372-439, giving a major $45 \mathrm{kDa}$ band. By 2-D PLDS, it is found that $\mathrm{B}_{4} \mathrm{C}$ NPs completely ablate bioluminescence, while $\mathrm{Cu}$ and $\mathrm{Fe}_{2} \mathrm{O}_{3}$ NPs yield a unique bimodal negative decay rate, $-7.67 \times 10^{3}$ and $-3.50 \times 10^{1}$ relative light units respectively. $\mathrm{Cu} \mathrm{NPs}$, in particular, give a remarkable $271 \%$ change in enzyme activity. Molecular dynamics simulations in water predicted that the surfaces of metal oxide NPs become capped with metal hydroxide groups under physiological conditions, while the surface of $\mathrm{B}_{4} \mathrm{C}$ becomes populated with boronic acid or borinic acid groups. These predictions are supported by the experimentally determined zeta potential. Thin layer chromatography patterns further support this conception of the NP surfaces, where stabilizing interactions were in the order ionic $>$ polar $>$ non-polar for the series tested. Conclusion: Overall the results suggest that $\mathrm{B}_{4} \mathrm{C}$ and $\mathrm{Cu}$ NP functional dynamics on enzyme biochemistry are unique and should be examined further for potential ramifications on other model, physiological or disease-relevant enzymes.

Keywords: 2-dimensional fluorescence difference, 2-D FDS, AUC, corrected light intensity emitted, emission wavelength, excitation wavelength, wavelength of max intensity, RLU

\section{Introduction}

Nanoparticle (NP) interactions with proteins and other molecules within the biological milieu have been termed the nano-bio interface. This new field has created great excitement within the biomaterials and engineering community. ${ }^{1-7}$ Recently, the anticancer activity of zinc oxide ( $\mathrm{ZnO}$ ) NPs has been shown by our group and several others and is now considered a nanoscale chemotherapeutic. ${ }^{8-10}$ Furthermore, the antibacterial activity of $\mathrm{ZnO}$ NPs has recently been linked to its ability to serve as a biomimetic inhibitor of the beta-galactosidase enzyme. ${ }^{11}$ Indeed nickel oxide $(\mathrm{NiO})$, magnesium oxide $(\mathrm{MgO})$ and $\mathrm{ZnO}$ possess some inherent catalytic activity themselves. ${ }^{12-14}$ Strikingly, NiO NPs have been shown to restore the function of fragmented enzyme that is nonfunctional in solution. ${ }^{3}$ Thus, the biochemical activity of physiological metal oxide NPs including 
zinc, iron, magnesium and others and their functional impact on enzymes are of tremendous interest but have never before been directly compared. Furthermore, studies on some NP compositions suggest that boron carbide $\left(\mathrm{B}_{4} \mathrm{C}\right)$ NPs may disturb RNA-protein interactions and that copper $(\mathrm{Cu}) \mathrm{NPs}$ may strongly influence protein secondary structure, yet the effect of these NPs on biochemical activity remains unexplored. ${ }^{15,36}$

What is known about NP-protein interaction is based primarily on transport proteins or those which are highly prevalent in blood such as albumin. ${ }^{7,15-19}$ In these cases, a variety of different techniques were employed to investigate NP-protein interaction, including (but not limited to) circular dichroism (CD), Raman, far UV and infrared spectroscopy, as well as isothermal calorimetry. ${ }^{15-19,20}$ Fluorescence spectroscopy tends to be more quantitative, ${ }^{16}$ and fluorescence difference spectroscopy (FDS) has been used to investigate changes in protein conformation and adsorption to the surface of derivatized silica. ${ }^{21}$ Interaction of $\mathrm{ZnO}$ NPs with fibrinogen, globulins and albumin resulted in a marked change in the tryptophan (Trp) emission spectra compared to the same proteins in solution or in contact with other NPs. ${ }^{17}$ Luciferase (Luc) is often used as a model enzyme whose structure ${ }^{22-26}$ is such that the fluorescence of Trp moieties in the hinge region flanking its active site provide a sensitive probe of conformational changes. ${ }^{27,28}$ Two-dimensional spectroscopy (performed by independent scanning of excitation and emission frequencies) provides an excellent quantitative measure with which to compare conformational changes induced by various NPs upon their interaction to Luc.

In concert with the effects of NPs on protein conformation, interaction of NPs with enzymes has been shown to stabilize, activate or inhibit them. ${ }^{11,29-32}$ In addition to fluorescence, the exquisite sensitivity of the bioluminescence produced by Luc and its detection by photoluminescence (PL) spectroscopy have been widely exploited in biotechnology and more recently in nanobiotechnology.,3,29,35 Bioluminescence resonance energy transfer between Luc and NPs may be a potential means of amplifying and increasing signal to noise in biosensor applications. ${ }^{4,33-35}$ Mapping the bioluminescence difference spectra in 2-dimensions (excitation and emission) provides an excellent quantitative measure with which activity changes induced by various NPs upon their interaction with Luc can be compared. More importantly, area under the curve (AUC) analysis of the kinetics provides a new way to compare the functional impact of NP.

\section{Materials and methods Materials}

ZnO NPs obtained from Dr G Glaspell (Virginia Commonwealth University) and NiO NPs obtained from Dr K Ghosh (Department of Physics, Missouri State University) were synthesized as previously described. ${ }^{10}$ All NPs used were of high purity $(>97 \%)$ with size specifications in the nanoscale $(<100 \mathrm{~nm}) . \mathrm{B}_{4} \mathrm{C}, \mathrm{Fe}_{2} \mathrm{O}_{3}$ and $\mathrm{Cu}$ nanopowders were purchased from PlasmaChem GmbH (Berlin, Germany). MgO nanopowder was purchased from Sigma-Aldrich (St. Louis, MI, USA). The NPs were washed with double-distilled deionized water, $70 \%$ ethanol/water and ethanol and stored dry prior to use. QuantiLum r-Firefly Luc (Ppy Luc, molecular weight [MW] $61 \mathrm{kDa}, 14.37 \mathrm{mg} / \mathrm{mL}$ ) and the Luc Assay System were obtained from Promega (Madison, WI, USA) and prepared and stored as described by Käkinen et al. ${ }^{32}$ They were subsequently diluted to a $1 \mathrm{mg} / \mathrm{mL}(16.4 \mu \mathrm{M})$ stock solutions in $0.01 \mathrm{mM}$ PBS (pH adjusted to 7.8 with $0.01 \mathrm{~N} \mathrm{NaOH}$ ). D-luciferin (high-performance liquid chromatography [HPLC], 99\% purity, monosodium salt) was purchased from Pierce Biotechnology (Waltham, MA, USA) and suspended in PBS (0.01 mM, pH 7.8) for a stock solution of $100 \mu \mathrm{g} / \mathrm{mL}$. Trypsin-EDTA $(0.05 \%)$ was purchased from Life Technologies (Waltham, MA, USA), and GelCode Blue Safe Protein Stain was purchased from Thermo Scientific (Waltham, MA, USA). All steady-state fluorescence and bioluminescence measurements (2-dimensional FDS [2D-FDS], intrinsic fluorescence, PL) were conducted on SpectraMax i3x multimode microplate reader at $25^{\circ} \mathrm{C}$ (Molecular Devices, (San Jose, CA, USA)) equipped with a Xenon flash lamp using 96-well black polypropylene microplates.

\section{Intrinsic fluorescence measurements}

Luc (1.64 $\mu \mathrm{M}$ in 0.01 M PBS, pH 7.8) excitation and emission spectra were recorded between $250-310 \mathrm{~nm}\left(\lambda_{\mathrm{em}}=342 \mathrm{~nm}\right)$ and 315-450 $\mathrm{nm}\left(\lambda_{\mathrm{ex}}=295 \mathrm{~nm}\right)$, respectively. Excitation and emission slit width was fixed at $5 \mathrm{~nm}$. For studying NP alterations in Luc fluorescence, Luc samples were manually titrated with successive $10 \mu \mathrm{L}$ additions of NP solutions $(100 \mu \mathrm{g} / \mathrm{mL}$, in double-distilled water $\left.\left[\mathrm{ddH}_{2} \mathrm{O}\right]\right)$ to final NP concentrations of $10-100 \mu \mathrm{g} / \mathrm{mL}$, with 11 samples in total. Luc-NP samples were homogenized and incubated for $30 \mathrm{~min}$ prior to measurement $\left(25^{\circ} \mathrm{C}\right)$. Concentration and inner filter effects were corrected by zeroing measurements of Luc with each NP to identically prepare Luc- $\mathrm{ddH}_{2} \mathrm{O}$ samples (absent NPs). The recorded spectra were corrected and analyzed using SigmaPlot v12.3.

\section{Fluorescence measurements of D-Luciferin \pm NPs}

To verify that the NP complexation occurred to Luc and not D-luciferin (substrate), intrinsic fluorescence of D-luciferin was conducted as already described. D-luciferin (prepared as outlined already) was incubated with $100 \mu \mathrm{g} / \mathrm{mL}$ or $10 \mu \mathrm{g} / \mathrm{mL}$ 
NP solutions, at a 1:1 ratio, for a final $w / v$ ratio of $1: 1$ and 10:1. Excitation and emission spectra were recorded between $250-500 \mathrm{~nm}\left(\lambda_{\mathrm{em}}=530 \mathrm{~nm}\right)$ and $450-650 \mathrm{~nm}\left(\lambda_{\mathrm{ex}}=390 \mathrm{~nm}\right)$, respectively. Concentration and inner filter effects were corrected as already described.

\section{Data analysis}

Luc and D-luciferin fluorescence data spectra were obtained from the instrument, and raw baseline measurements were corrected by subtracting appropriate buffer background fluorescence values using SpectraMax Pro 6.5 software. Inner filter effects and instrumental variation were corrected by Luc or D-luciferin standard curve of fluorescence $\left(\mathrm{F}_{\mathrm{em}}\right)$ at $\lambda_{\mathrm{ex}}=280 \mathrm{~nm}$ and $\lambda_{\mathrm{ex}}=295 \mathrm{~nm}$. This was converted into corrected intensity values $\left(\mathrm{I}_{\mathrm{em}}\right)$ using the well-known Lambert-Beer's law:

$$
\mathrm{I}_{\mathrm{em}}=\ln (10) \cdot \mathrm{I}_{\mathrm{ex}} \cdot \varepsilon_{280} \cdot \mathrm{C} \cdot 1
$$

where $\mathrm{I}_{\mathrm{ex}}$ is the incident excitation intensity, $\varepsilon$ is the molar absorption coefficient for Luc $\left(3.92 \times 10^{4} \mathrm{M}^{-1} \mathrm{~cm}^{-1}, 280 \mathrm{~nm}\right)$ or D-luciferin $\left(6.29 \times 10^{3} \mathrm{M}^{-1} \mathrm{~cm}^{-1}, 280 \mathrm{~nm}\right)$ and $\mathrm{C}$ is the concentration of the fluorophore. Fluorescence emission is proportional to number of excited states present in solution. The standard curve $\left(\mathrm{C}_{1}\right)$ was used to obtain the concentration of fluorophore present in the sample wells $\left(\mathrm{C}_{2}\right)$ for the abovementioned corrected intensity values.

$$
\frac{\mathrm{I}_{\mathrm{em}(\mathrm{ref})}}{\mathrm{I}_{\mathrm{em} \text { (sample) }}}=\frac{\mathrm{C}_{1}}{\mathrm{C}_{2}}
$$

The Trp emission spectra, including the wavelength $\left(\max \lambda_{\mathrm{em}}\right)$ at which fluorescence intensity is maximal $\left(\mathrm{I}_{\max }\right)$ is highly sensitive to changes in local Trp microenviorment. Integrated fluorescence intensity, AUC, computed as the area under the curve, is a measure for the relative fluorescence quantum yield and indicates changes in the overall protein environment. ${ }^{37}$ For each spectra, Luc fluorescence $\left(\lambda_{\text {ex }}=\right.$ $295 \mathrm{~nm}$ ) was integrated between 300 and $380 \mathrm{~nm}$ using the Gaussian curve fitting function in SigmaPlot v13.0. Fluorescence ratio intrinsic basis states analysis (FRIBSTA) utilizes the $I_{e m}, I_{\max }$ and AUC to give a fractional area spectrum, useful for comparing the effects of denaturants on protein stability and conformation. ${ }^{38}$ Accordingly, Luc-NP spectra were normalized to the Luc-only spectra and plotted as $\mathrm{I}_{\mathrm{em}} / \mathrm{AUC}$ or $\Delta \mathrm{I}_{\max } /$ AUC. ${ }^{27}$ This was done for better interpretation of the overall photochemical excitation and de-excitation processes attributed to Luc possessing dual-Trp residue. Fluorescence analysis of D-luciferin was conducted in a similar manner with extraction of $\mathrm{I}_{\mathrm{em}}$ from instrumental $\mathrm{F}_{\mathrm{em}}$ values; however, because the photoexcitation and emission process is attributed entirely to each molecule, the functional activation resides on the excitation efficiency of D-luciferin, $\mathrm{I}_{\mathrm{em}} \cdot(\mathrm{AUC})^{-1}$.

\section{Two-dimensional fluorescence difference spectroscopy}

2-D FDS measurements were run according to specifications outlined previously ${ }^{39}$ with modifications. Fluorescence excitation $\left(\lambda_{\mathrm{ex}}, 250-310 \mathrm{~nm}\right)$ and emission $\left(\lambda_{\mathrm{em}}\right.$, $280-400 \mathrm{~nm}$ ) wavelengths of Luc were scanned at $2 \mathrm{~nm}$ increments with $9 \mathrm{~nm}$ and $15 \mathrm{~nm}$ slit widths for $\lambda_{\text {ex }}$ and $\lambda_{\text {em }}$, respectively. The measured value was corrected for background fluorescence and the resulting values were plotted as fluorescence emission vs excitation sensitivity, measured in relative fluorescence units (RFU).

\section{Bioluminescence spectra and kinetic measurements of Luc with/without NPs}

Ppy Luc bioluminescence spectra were conducted as detailed by manufacturer's instructions and described by Käkinen et al. ${ }^{32}$ Luc kinetic and bioluminescence experiments were conducted using $20 \mu \mathrm{L}$ of $0.05 \mathrm{mg} / \mathrm{mL}$ Luc $(0.82 \mu \mathrm{M})$ and $100 \mu \mathrm{L}$ of reconstituted Luc reagent (LR) in 96-well opaque polypropylene microplates. Signal was recorded on a SpectraMax i3x multi-mode microplate reader equipped with LED capability. Instrument sensitivity was standardized using serial dilution of Luc samples $\left(50 \mu \mathrm{M}-5 \times 10^{-9} \mu \mathrm{M}\right)$ with $100 \mu \mathrm{L}$ LR. Initial bioluminescence spectra were measured between 450 and $750 \mathrm{~nm}$ with $150 \mathrm{~ms}$ integration at $\mathrm{pH} 7.8$ and a temperature of $25^{\circ} \mathrm{C}$. The estimated mixing time was $15 \mathrm{~s}$. Kinetic measurements were recorded directly after initial bioluminescence $\left(\mathrm{t}_{0}=60 \mathrm{~s}\right)$ over $600 \mathrm{~s}$ at 21 data points. Bioluminescence intensity (relative light units [RLU]) readings were measured between 450 and $750 \mathrm{~nm}$ with $150 \mathrm{~ms}$ integration. For NP-mediated alterations in Luc bioluminescence and kinetics, the bioluminescence spectra $\left(\mathrm{t}_{0}=15 \mathrm{sec}\right)$ and kinetic readings $\left(\mathrm{t}_{0}=60 \mathrm{sec}\right)$ were recorded identically (as discussed already) with pre-incubated Luc-NP mixtures at a $1: 1 \mathrm{w} / \mathrm{v}$ and $10: 1 \mathrm{w} / \mathrm{v}$ ratio, respectively. Briefly, for the $1: 1 \mathrm{w} / \mathrm{v}$ Luc-NP mixture, $100 \mu \mathrm{L}$ Luc $(100 \mu \mathrm{g} / \mathrm{mL})$ was added to $100 \mu \mathrm{L}$ of homogenized NP $(100 \mu \mathrm{g} / \mathrm{mL})$ and incubated under mild agitation $\left(30 \mathrm{~min}, 25^{\circ} \mathrm{C}\right)$. The 10:1 w/v Luc:NP mixtures were prepared identically with a 10 -fold dilution of the $100 \mu \mathrm{g} / \mathrm{mL}$ NP samples. Final Luc concentration in Luc-NP samples was $0.05 \mu \mathrm{g} / \mathrm{mL}$ for all trials. 
Immediately prior to measurements, $20 \mu \mathrm{L}$ of either $1: 1 \mathrm{w} / \mathrm{v}$ or 10:1 w/v Luc-NP mixtures were added to $100 \mu \mathrm{L}$ of $\mathrm{LR}$.

\section{Thin layer chromatography (TLC)}

NP solutions with a concentration of $10 \mathrm{mg} / \mathrm{mL}$ in water were prepared for $\mathrm{ZnO}, \mathrm{Cu}, \mathrm{Co}_{3} \mathrm{O}_{4}, \mathrm{NiO}, \mathrm{MgO}, \mathrm{Si}_{3} \mathrm{~N}_{4}, \mathrm{~B}_{4} \mathrm{C}$ and $\mathrm{Fe}_{2} \mathrm{O}_{3}$. A saturated amino acid solution was prepared by adding amino acids - lysine (Lys), glutamine (Glu), arginine (Arg), histidine (His), tyrosine (Tyr) and threonine (Thr) - to $1 \mathrm{~mL} \mathrm{ddH_{2 }} \mathrm{O}$. Spotting solutions of amino acid and NPs were prepared in a $1: 1$ ratio by volume. In total, $1 \mu \mathrm{L}$ of the mixture was applied to a $13 \times 19 \mathrm{~cm}$ TLC plate. The plate was allowed to dry and placed in $10 \mathrm{~mL}$ of elution buffer (9:1 ratio of ethanol: acetic acid [1 M]). The plate was left for 1 hour to allow the eluent to elute up the plate. This plate was dried, sprayed with ninhydrin staining solution and placed in a drying oven at $60^{\circ} \mathrm{C}$ for 10 minutes. Possible interactions/reactions between the amino acids and NPs were determined by comparing $R_{f}$ values.

\section{Limited proteolysis with trypsin}

To investigate the structural perturbation of Luc in the presence of NP complexation, limited proteolysis by trypsin was accomplished. Briefly, Luc-NP samples were prepared at a $1: 1 \mathrm{w} / \mathrm{v}$ ratio $(0.5 \mathrm{mg} / \mathrm{mL})$ with a final volume of $10 \mu \mathrm{L}$, which were homogenized, centrifuged and incubated for $5 \mathrm{~min}$ at $25^{\circ} \mathrm{C}$. The Luc-NP samples were incubated with $2 \mu \mathrm{L}$ trypsin $(0.05 \% \mathrm{w} / \mathrm{v})$ for the specified time periods $(5 \mathrm{~min}, 15 \mathrm{~min}$, $30 \mathrm{~min}$ and $60 \mathrm{~min}$ ). Samples were run on sodium dodecyl sulfate polyacrylamide gel electrophoresis (SDS-PAGE) (100 V, 2 hours) and visualized using GelCode Blue Safe Protein. Gels were imaged with a BioRad Molecular Image Gel DocXR+ and analyzed with Image Lab software.

\section{Luc-NP binding}

To determine the quantity of Luc binding to NPs, $1 \mathrm{mg} / \mathrm{mL}$ NPs and $0.5 \mathrm{mg} / \mathrm{mL}$ Luc were added to a final volume of $30 \mu \mathrm{L}$ and spun down for 1,2 and 3 hours at $14,000 \mathrm{rpm}$ at $4{ }^{\circ} \mathrm{C}$. The quantity of protein in the supernatant unbound to the NPs was obtained using Nanodrop 8000 spectrophotometer.

\section{Examination of the effect of NPs on the secondary structure of Luc}

The secondary structure of untreated Luc and Luc-NP mixtures was examined by CD spectroscopy (Chirascan; Applied Photophysics Ltd., Leatherhead, UK). Luc solution was prepared to a concentration of $200 \mu \mathrm{g} / \mathrm{mL}$. Cu and $\mathrm{B}_{4} \mathrm{C}$ NP solutions were prepared in deionized water with two different concentrations, $200 \mu \mathrm{g} / \mathrm{mL}$ and $20 \mu \mathrm{g} / \mathrm{mL}$. Luc-NP solutions with 1:1 and 10:1 ratios (Luc: NP, w/w) were then prepared by mixing equal amounts of Luc and NP solutions. Prior to mixing, NP solutions were homogenized with a probe sonicator (VCX 130; Sonics \& Materials, Inc., Newtown, CT, USA) for $2 \mathrm{~min}$ at 50\% amplitude. The Luc-NP mixtures were incubated under ambient conditions at 200 rpm for $30 \mathrm{~min}$ and examined using CD spectroscopy. The final concentration of Luc in every CD sample was $100 \mu \mathrm{g} /$ $\mathrm{mL}$, and the volume of each sample was $200 \mu \mathrm{L}$. CD in the UV range (200-260 nm) was monitored with a $0.1 \mathrm{~mm}$ path length quartz cell at ambient temperature. The CD spectra were recorded with a step size of $1.0 \mathrm{~nm}$, bandwidth $0.5 \mathrm{~nm}$ and an averaging time of $3.0 \mathrm{~s}$. CD spectra processing and background subtractions were performed using Pro-Data Viewer software (Applied Photophysics Ltd.). The CD data

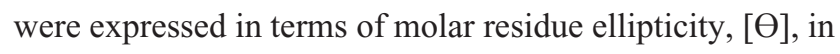
$\operatorname{deg} \mathrm{cm}^{2} \mathrm{dmol}^{-1}$. The distribution of secondary structures was estimated from the obtained CD spectra by the Dichroweb software package ${ }^{42-44}$ with the K2D algorithm. A total of six samples were measured, and all data were presented as mean \pm standard deviation. Data were compared using a Student's $t$-test with equal variances. A value of $P<0.05$ was considered statistically significant.

\section{MTT assay}

3T3 mouse fibroblast cells (American Type Culture Collection [ATCC]) were seeded on a 96-well plate with 5,000 cells/well and allowed to grow for 24 hours in DMEM with 10\% FBS and $1 \%$ penicillin/streptomycin. After 24 hours, the medium was changed and the metal oxide treatments were added $\left(\mathrm{Fe}_{2} \mathrm{O}_{3}, \mathrm{NiO}, \mathrm{MgO}, \mathrm{B}_{4} \mathrm{C}, \mathrm{ZnO}\right.$ and $\left.\mathrm{Cu}\right)$, all at a concentration of $200 \mu \mathrm{g} / \mathrm{mL}$ in the same DMEM solution as before. Each treatment was tested on four sample wells. There were also four wells with cells that did not receive treatment and four wells that did not get any cells. After 24 hours with the treatment, the treatment was removed and the wells were rinsed with PBS and then a 1:20 mix of MTT: indicator-free DMEM was added to each well with $110 \mu \mathrm{L}$ per well and left to metabolize for 5 hours in the incubator. After 5 hours, $85 \mu \mathrm{L}$ of the mixture was removed from each well and $75 \mu \mathrm{L}$ of dimethyl sulfoxide was added to each well to solubilize the crystals. The plate was then put on an orbital shaker at $37^{\circ} \mathrm{C}$ at 175 revolutions/ minute. After 15 minutes on the orbital shaker, the plate was then read on a Synergy H1 Hybrid Multi-Mode Microplate Reader for absorbance at a wavelength of $562 \mathrm{~nm}$.

\section{Results}

Transmission electron microscopy confirmed the NP size and morphology prior to the binding of Luc, which was demonstrated by the particle size and zeta potential (ZP) 
Table I Physical characteristics of NPs before and after binding of Luc

\begin{tabular}{llll}
\hline $\mathbf{N P} \pm$ Luc & Size $(\mathbf{n m})$ & Zeta potential $(\mathbf{m V})$ & PDI \\
\hline $\mathrm{ZnO} *$ & 138,1143 & $25.3,-15.5$ & $0.16,0.35$ \\
$\mathrm{Cu}$ & 124,174 & $13.5,-13.6$ & $0.86,0.33$ \\
$\mathrm{~B}_{4} \mathrm{C}^{*}$ & 163,556 & $-32.5,-16.2$ & $0.16,0.4$ \\
$\mathrm{Fe}_{2} \mathrm{O}_{3}$ & 256,1043 & $24.5,-11.8$ & $0.33,0.58$ \\
$\mathrm{MgO}$ & 272,311 & $17.8,-19.7$ & $0.57,0.36$ \\
$\mathrm{NiO}$ & 56,523 & $48.3,-18.2$ & $0.12,0.36$
\end{tabular}

Notes: ${ }^{¥} \mathrm{~A}$ TEM analysis was previously reported for $\mathrm{ZnO}$ and $\mathrm{B}_{4} \mathrm{C}$ NP, but was repeated here to confirm nanoscale particles for all compositions studied prior to binding protein. ${ }^{10,36}$ DLS, PDI and ZP analysis of the NPs before (left value) and after introduction of Luc (right value). The NP concentration range was 7.3-24 mM.

Abbreviations: NPs, nanoparticles; Luc, luciferase; TEM, transmission electron microscopy; PDI, polydispersity index; ZP, zeta potential.

analysis as shown in Table 1. Furthermore, the same techniques were used to characterize the NPs after binding with Luc. As expected, interactions between these NPs and Luc protein caused an increase in hydrodynamic diameter for all NPs (Table 1).

The changes in the NP size and ZP demonstrate protein-NP interaction consistent with a prior study with $\mathrm{ZnO}$ NPs. ${ }^{18}$ The decrease in polydispersity index for $\mathrm{Cu}$ and increase in $\mathrm{ZP}$ for $\mathrm{B}_{4} \mathrm{C}$ in the presence of Luc suggest a fundamental difference in their physicochemical interaction and were explored further for their impact on Luc enzyme structure-function by 2-D FDS and 2-dimensional photoluminescence difference spectroscopy (2-D PLDS), as described further in the following text.

2-D FDS can be used to measure protein-NP interaction; ${ }^{39}$ here, it was performed comparatively by plotting the change in intensity and AUC for Luc as a function of the NP type to which it was exposed (Figure 1).

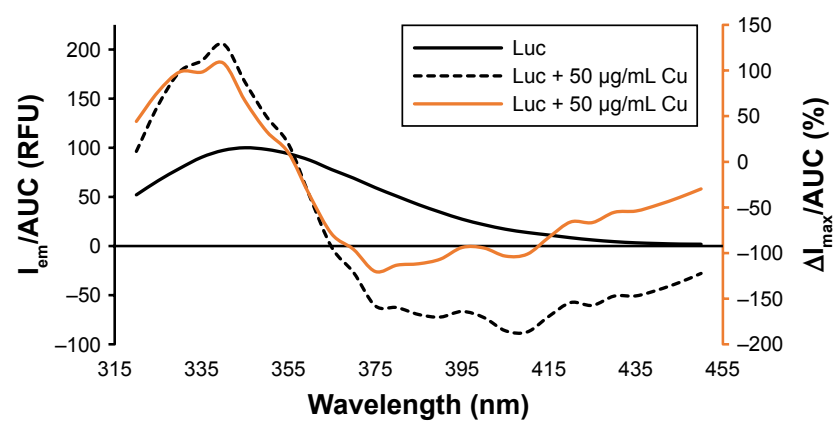

Figure I 2-D FDS spectrum of Luc alone and Luc in the presence of Cu NPs at $25^{\circ} \mathrm{C}$ in 0.0I M PBS ( $\mathrm{pH}$ 7.8). The $y$ axis represents $\mathrm{I}_{\mathrm{em}} / \mathrm{AUC}$ in relative absorbance units RFU or the change in $\Delta \mathrm{I}_{\max }$ /AUC (\%). The $\mathrm{x}$ axis represents emission wavelength $(315-455 \mathrm{~nm})\left(\lambda_{\mathrm{ex}}=295 \mathrm{~nm}\right)$. The data are tabulated in Table 2 for all NPs at $50 \mu \mathrm{g} / \mathrm{mL}$ NP. The black line represents I /AUC (corresponding to the black axis) and the orange line represents $\Delta I_{\max } / A U C$ (\%) (corresponding to the orange axis). Abbreviations: 2-D FDS, 2-dimensional fluorescence difference spectroscopy; Luc, luciferase; NPs, nanoparticles; AUC, area under the curve; RFU, relative fluorescence units.
Table 2 Data comparison on the maximal fluoresence emission, intensity and $A \cup C$

\begin{tabular}{llll}
\hline $\mathbf{N P}$ & Max $\lambda_{\text {em }}(\mathbf{n m})^{(\mathbf{a})}$ & $\Delta \mathbf{I}_{\max }(\%)$ & $\Delta$ AUC (\%) \\
\hline $\mathrm{ZnO}$ & $34 \mathrm{I} \pm 2$ & 67.87 & 66.55 \\
$\mathrm{~B}_{4} \mathrm{C}$ & $340 \pm 4$ & 83.98 & 86.82 \\
$\mathrm{Cu}$ & $338 \pm 7$ & 85.34 & 84.26 \\
$\mathrm{Fe}_{2} \mathrm{O}_{3}$ & $340 \pm 2$ & 3.96 & 7.25 \\
$\mathrm{MgO}$ & $342 \pm 4$ & -2.00 & 1.76 \\
$\mathrm{NiO}$ & $34 \mathrm{I} \pm 2$ & 43.36 & $45.6 \mathrm{I}$ \\
\hline
\end{tabular}

Note: a Mean \pm SD.

Abbreviations: AUC, area under the curve; NP, nanoparticle.

As shown in Figure 1, a concentration-dependent change in the 2-D FDS pattern was observed, where the most overt change in both maximal fluorescence intensity $\left(\mathrm{I}_{\max }\right)$ and AUC was for $\mathrm{Cu}-\mathrm{NP}$. The remaining data of the series by this criterion are summarized in Table 2.

As summarized in Table 2, $\mathrm{B}_{4} \mathrm{C}$ and $\mathrm{Cu}$ NPs caused the greatest change in 2-D FDS as reflected in the maximal fluorescence intensity, its change $\left(\Delta \mathrm{I}_{\max }\right)$ and AUC analysis. While the fluorescence wavelength was unchanged, $\mathrm{I}_{\max }$ and AUC changes are presumed to be due to Trp residues in the flexible hinge region, implying an excellent in situ read out of the protein's conformation..$^{27,28}$

The dramatic change in AUC fluorescence for $\mathrm{Cu}$ and $\mathrm{B}_{4} \mathrm{C}$ suggested potential conformational changes induced in Luc upon interaction with these NPs. To further examine this, limited trypsin digestion was performed followed by protein gel electrophoresis analysis. Here, degradation is being caused by trypsin proteolysis. The rate of proteolysis is expected to increase for an unfolded versus a folded protein (Figure 2).

As shown in Figure 2A and B, Luc-Cu samples degraded faster than Luc- $\mathrm{B}_{4} \mathrm{C}$ or Luc-only controls. These data are consistent with the hypothesis that absorption of Luc to $\mathrm{Cu}$ NPs causes partial unfolding and, thus, greater accessibility for cleavage. Similar to controls, $\mathrm{B}_{4} \mathrm{C}$ NPs showed an initial band migrating at an apparent MW of approximately $45 \mathrm{kDa}$. Although it was not possible to unambiguously identify the Luc fragment corresponding to this band from the electrophoresis analysis, the trypsin cleavage positions capable of producing such a fragment are limited. Trypsin cleavage occurs only at Lys $(\mathrm{K})$ or $\operatorname{Arg}(\mathrm{R})$ residues, with the neighboring environment determining the probability of any particular cleavage. Notably, cleavage at a particular site implies that this site is accessible to trypsin and not completely occluded by contact with the NPs. We applied the Cleavage Prediction with Decision Trees algorithm ${ }^{40}$ to determine the probability of cleavages that yield fragments with a mass of $45 \pm 4 \mathrm{kDa}$. For the shortest durations shown in Figure 2A and B, it can be assumed that most Luc molecules are uncleaved or have 

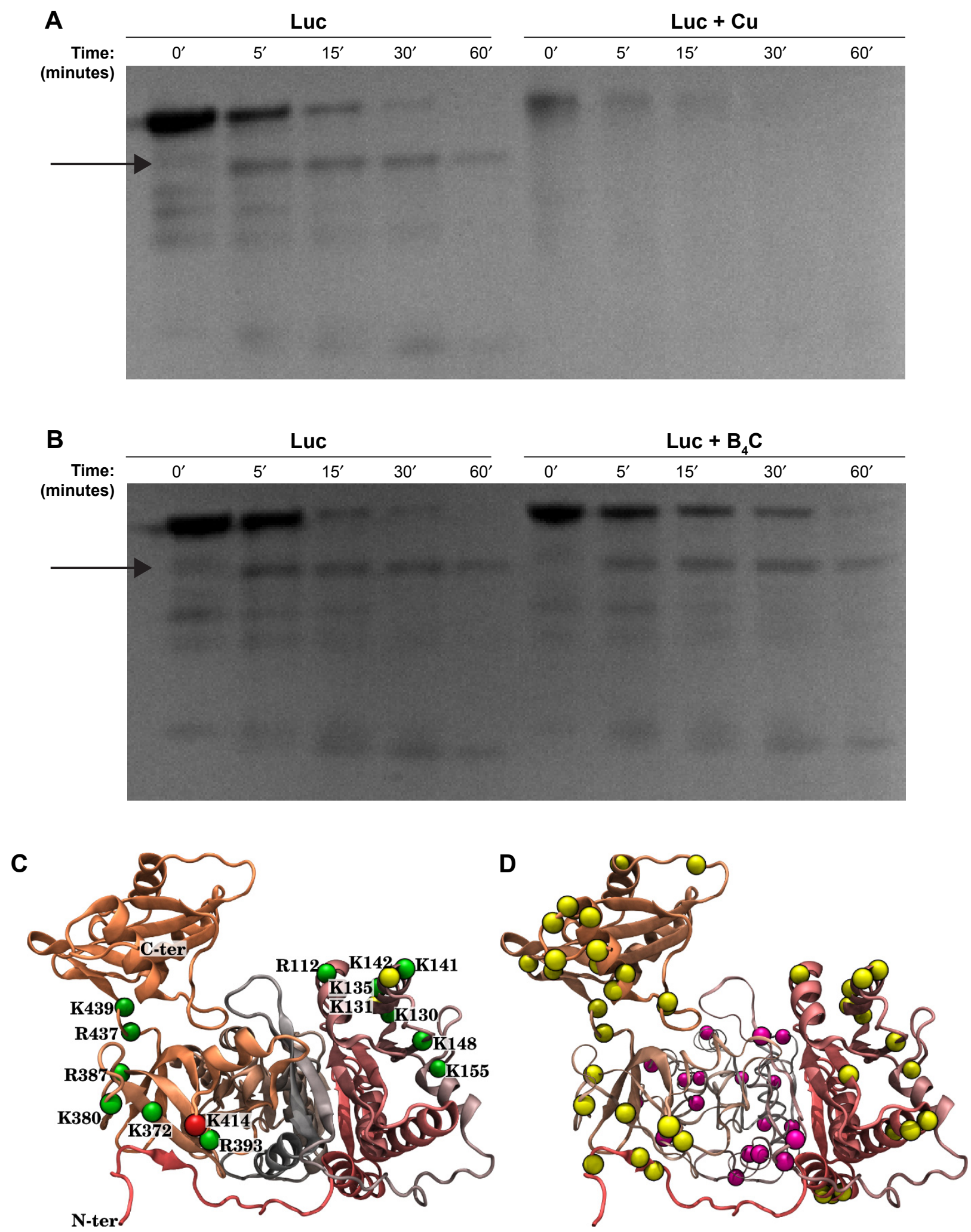

Figure 2 SDS-PAGE analysis of Luc tryptic digests in presence of $(\mathbf{A}) \mathrm{Cu}$ or (B) $\mathrm{B}_{4} \mathrm{C}$ NP. The arrow denotes the lane corresponding to a mass of $45 \pm 4 \mathrm{kDa}$, assigned based on prior gels relative to molecular weight markers and the known molecular weight of Luc in the main band above. (C) Possible locations of a single cleavage of Luc by trypsin resulting in the observed $45 \pm 4 \mathrm{kDa}$ fragments. Luc (PDB ID: ILCI) is shown in a secondary-structure representation and cleavage locations are highlighted by spheres. The color of the spheres indicates the cleavage probability as predicted by the algorithm, ${ }^{40}$ with green, yellow and red, respectively, denoting probabilities $P>0.85,0.85 \leq P \leq 0.6$ and $P<0.6$. (D) Cleavage locations that preclude formation of $45 \pm 4 \mathrm{kDa}$ fragments (magenta) and those locations that are consistent with the formation of $45 \pm 4 \mathrm{kDa}$ fragments by one or more cleavage events (yellow).

Abbreviations: SDS-PAGE, sodium dodecyl sulfate polyacrylamide gel electrophoresis; Luc, luciferase; NP, nanoparticle. 



Figure 3 Effect of NPs on Luc kinetics and PL spectra. (A) Time dependence of Luc activity in the presence of Fe $\mathrm{O}_{3}$ and $\mathrm{Cu}$ NP. (B) Luminescence as a function of wavelength for Luc control and in the presence of $\mathrm{Cu}, \mathrm{Fe}_{2} \mathrm{O}_{3}$ and $\mathrm{B}_{4} \mathrm{CNP}$.

Abbreviations: NPs, nanoparticles; Luc, luciferase; PL, photoluminescence.

been cleaved only once. Figure $2 \mathrm{C}$ shows the 15 locations of Luc where a single cleavage can yield $45 \pm 4 \mathrm{kDa}$ fragments, occupying just two regions of the protein. The Luc image is based on the X-ray-derived structure (Protein Data Bank identifier [PDB ID]: $1 \mathrm{LCI})^{23}$ with atomic coordinates for missing residues as estimated by MODELLER software. ${ }^{41}$ Based on protected regions of the protein not being cleaved, these results seem to imply that either residues $372-439$ or residues $112-155$ remain accessible to trypsin when Luc is adsorbed to $\mathrm{B}_{4} \mathrm{C}$ NP. Even when multiple cleavage events are taken into account, there remain some limitations on where cleavage can occur to form $45 \pm 4 \mathrm{kDa}$ fragments, as shown in Figure 2D. We hypothesize that cleavage of the relatively independent $\mathrm{C}$-terminal domain ${ }^{23}$ at residue 437 or 439 is a major contributor to the band at $\sim 45 \mathrm{kDa}$.

Next, the impact of protein-NP interaction on Luc enzyme activity was investigated by 2-D PLDS. The rapid kinetics of the enzyme was monitored 60 seconds after the injection of the Luciferin substrate. The decay rate, PL spectra and AUC were plotted over the course of approximately one half-life (11 minutes or 660 seconds), as shown in Figure 3A and B.

As shown in Figure 3, and consistent with enzyme denaturation by $\mathrm{Cu}$ NPs, nanobiocatalysis was delayed causing a negative decay rate within the rapid timespan of the experiment (60-660 seconds). The AUC increased accordingly. The decay rate for $\mathrm{Fe}_{2} \mathrm{O}_{3}$ NPs was also negative and unique relative to the other NPs. Quite surprisingly, in the presence of $\mathrm{B}_{4} \mathrm{C}$ NPs, no PL was catalyzed. These data suggested that the impact of nano-bio interaction on enzyme function may be more complicated than altering protein conformation. These data are summarized in Table 3.

The data in Table 3 when taken comparatively suggest some plausible mechanistic insight. In addition to partial protein denaturation causing loss of activity (as suggested in Figure 2), another potential explanation for the delayed onset and fine structure observed in the PL spectra for $\mathrm{Cu}$ and $\mathrm{Fe}_{2} \mathrm{O}_{3}$ is interaction between the NPs and the D-luciferin substrate rather than the protein itself. Given the intrinsic fluorescence of the luciferin substrate, its quantum efficiency could be obtained by integrating AUC for its excitation and emission in the presence of the NPs as per the following equation:

$$
\text { Relative } \phi_{\mathrm{f}}=\frac{\int_{0}^{\infty} \mathrm{I}\left(\lambda_{\mathrm{em}}\right) \mathrm{dt}}{\int_{0}^{\infty} \mathrm{I}\left(\lambda_{\mathrm{ex}}\right) \mathrm{dt}}
$$

where relative quantum yield, $\phi_{\mathrm{f}}$, and integrated intensity, I, were used to quantitatively assess overall changes in the energy transfer efficiency $\left(\phi_{f}\right)$ of D-luciferin. These plots were recorded at two different NP concentrations $(0.1$ or $0.01 \mathrm{~g} / \mathrm{mL})$. As shown in Figure 4, for most NPs, the change in quantum

Table 3 Effect of NPs on Luc kinetics and PL spectra

\begin{tabular}{llll}
\hline $\mathbf{N P}$ & $\lambda_{\text {em }}(\mathbf{n m})^{*}$ & $\begin{array}{l}\text { PL decay rate } \\
(\mathbf{R L U} / \mathbf{m i n})\end{array}$ & $\begin{array}{l}\Delta \text { in activity } \\
(\%)^{\mathbf{c}}\end{array}$ \\
\hline $\mathrm{ZnO}$ & $545 \pm 5$ & $9.17 \times 10^{3}$ & 45.8 \\
$\mathrm{Cu}$ & $545 \pm 5$ & $-7.67 \times 10^{3 *}$ & 271.0 \\
$\mathrm{~B}_{4} \mathrm{C}$ & $\mathrm{ND}$ & $\mathrm{ND}$ & $\mathrm{ND}$ \\
$\mathrm{Fe}_{2} \mathrm{O}_{3}$ & $550 \pm 5$ & $-3.50 \times 10^{1 *}$ & 31.3 \\
$\mathrm{MgO}$ & 560 & $2.67 \times 10^{4}$ & 20.4 \\
$\mathrm{NiO}$ & $545 \pm 5$ & $4.33 \times 10^{3}$ & 49.1
\end{tabular}

Notes: Luc control $\lambda_{\text {em }}=555-562 \mathrm{~nm}, 3.17 \times 10^{4} \mathrm{RLU} / \mathrm{min}$, change in activity ( $0 \%$ control). $\Delta$ in activity curve compares AUC for activity relative to control. *Values reported as mean $\pm S D(n=4)$. *Negative decay rate (luminescence/time $\geq 0$ ). ${ }^{t}$ Time period from initial luminescence $\left(t_{0}=60\right.$ seconds) to final luminescence $\left(\mathrm{t}_{\mathrm{f}}=660\right.$ seconds $)$.

Abbreviations: NPs, nanoparticles; Luc, luciferase; PL, photoluminescence; RLU, relative light units; AUC, area under the curve; ND, not detected. 


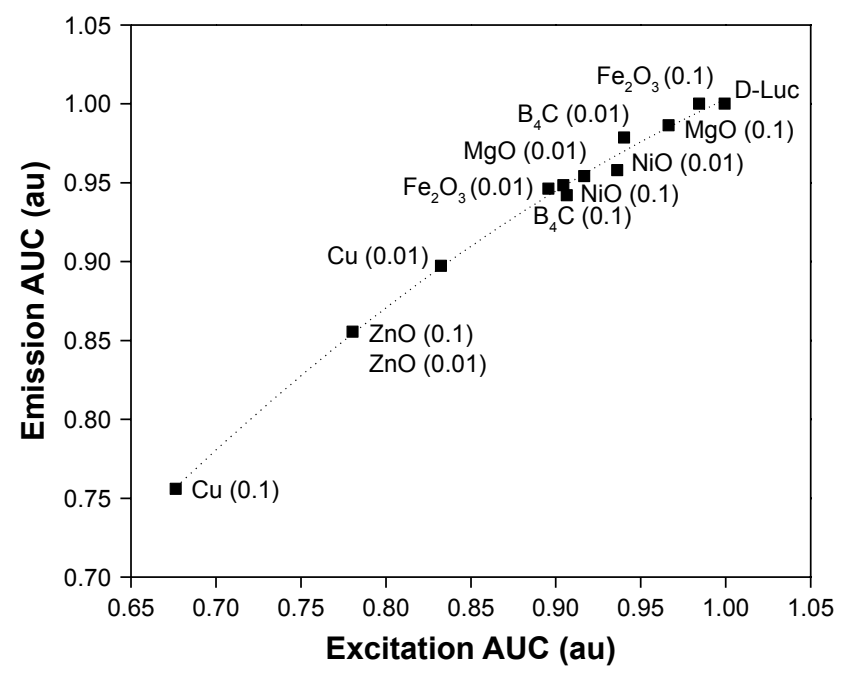

Figure 4 Change in emission-excitation of D-luciferin in the presence or absence of NPs. The relative $\phi_{f}(A \cup C)$ values are normalized such that the emission and excitation AUC values of the D-luciferin samples are I. NP concentrations are indicated in $\mathrm{mg} / \mathrm{mL}(0.1$ and $0.01 \mathrm{mg} / \mathrm{mL})$. The dotted line indicates the quadratic fit to the AUC data.

Abbreviations: NPs, nanoparticles; AUC, area under the curve.

yield from the luciferin-only control was negligible $\left(\left|\Delta \phi_{\mathrm{f}}\right| \leq 0.05\right)$. The exception is $\mathrm{Cu}$ NPs, particularly at the $0.1 \mathrm{~g} / \mathrm{mL}$ concentration, for which $\phi_{\mathrm{f}}=0.76$. ZnO NPs also slightly impeded D-luciferin photoexcitation, with $\phi_{\mathrm{f}} \approx 0.9$ at the two concentrations considered. Altogether, these data suggest that for most NPs, conformational changes in the enzyme due to interaction with the NPs underlie the changes in enzyme activity.

One major difficulty in understanding the physicochemistry of interactions between proteins and NPs is that the atomic-scale structure of the NP surfaces in an aqueous environment where they encounter enzymes are not well characterized. To approximate the chemical structure of the NP surfaces, molecular dynamics simulations were used to reconstruct $\mathrm{ZnO}, \mathrm{Cu}$ and $\mathrm{B}_{4} \mathrm{C}$ surfaces in water under ambient conditions. As shown in Figure 5A, 79\% and $73 \%$ of the undercoordinated $\mathrm{Zn}$ and $\mathrm{O}$ atoms of the pristine $\mathrm{ZnO}\{1010\}$ surface became capped with $\mathrm{OH}$ or $\mathrm{H}$ groups, respectively. Similarly, under-coordinated atoms of the $\mathrm{B}_{4} \mathrm{C}$ surface underwent chemical reactions with water to yield boranes and oxygen-containing boron moieties. Notably, $96 \%$ of surface boron atoms bound to carbon formed boronic acid moieties (Figure 5B) or, more rarely, borinic acid groups. Surface boron atoms not bound to carbon tended to form borane or diborane motifs. The $\mathrm{Cu}\{111\}$ surface, on the other hand, underwent much less modification. Only $29 \%$ of the under-coordinated surface atoms formed covalent bonds to water molecules (Figure 5C), leaving a majority of the $\mathrm{Cu}$ atoms free to make contact with solutes. In the experiments, these particles are stabilized by $3 \%$ oleic acid, which may impact water behavior at the surface.
Another advantage of Luc as a model enzyme is that its active site has also been well characterized. ${ }^{46}$ The key Trp moieties making conformational changes in the protein induced by NP interaction are measurable by 2-D FDS as already mentioned. A model for the substrate binding site is shown in Figure S1. ${ }^{25,26}$ In addition to glutamate and Tyr shown in the inset, site-directed mutagenesis and comparative homology studies also suggest the importance of His, Thr and Lys. ${ }^{28-30,40}$ Altered chromatographic elution has previously been used to gauge interactions to derivatized silica, and was used similarly here to investigate NP interaction with these different amino acids by TLC (Figure S2). The greatest migrational difference $\left(\%\right.$ control $\left.\mathrm{R}_{\mathrm{f}}\right)$ was seen for Lys that occurred to all NPs, likely indicative of ionic interactions. However, migration differences were seen for Glu and Thr, indicating that hydrogen bonding or polar type interactions may also contribute to interaction. Minor migration differences for Tyr and His do not rule out non-polar stabilizing interactions but would need to be extended to other non-polar amino acids to better determine their effect.

To confirm conformation changes suggested by the fluorescence, bioluminescence, gel and biochemical activity data by $\mathrm{Cu}$ and $\mathrm{B}_{4} \mathrm{C} \mathrm{NP}$, a final $\mathrm{CD}$ experiment was conducted. Figure 6A shows the CD spectra of Luc-Cu mixture with $1: 1$ and 10:1, and Figure $6 \mathrm{~B}$ presents their secondary structure distribution. Untreated (native) Luc was used as a control. The untreated Luc had two negative ellipticity values at 208 and $222 \mathrm{~nm}$ and contained 39.00\% $\alpha$-helix, 5.67\% $\beta$-sheet and $55.17 \%$ random coil structures. The Luc- $\mathrm{Cu}$ mixtures, on the other hand, showed significant reduction in ellipticity values. The $\alpha$-helix structure of the $\mathrm{Luc}-\mathrm{Cu}$ mixture with $10: 1$ ratio was decreased from $39.00 \%$ to $25.67 \%$, together with an increase of $\beta$-sheet from $5.67 \%$ to $24.67 \%$. Particularly, the $\alpha$-helix contents of the Luc- $\mathrm{Cu}$ mixture with 1:1 ratio were significantly decreased as compared with untreated Luc (18.23\%), along with a substantial increase of $\beta$-sheet (33.33\%). Figure 6C and D displays the CD spectra and the secondary structure distribution of $\mathrm{Luc}-\mathrm{B}_{4} \mathrm{C}$ mixture with two different ratios, respectively. The $\mathrm{CD}$ spectra of Luc- $\mathrm{B}_{4} \mathrm{C}$ mixture with 10:1 and 1:1 ratio showed remarkably lower ellipticity values as compared with untreated Luc, and the corresponding secondary structure distribution showed a trend similar to that of $\mathrm{Luc}-\mathrm{Cu}$ mixture. For 1:1 ratio, however, $\mathrm{B}_{4} \mathrm{C}$ NPs seemed to induce more conformational changes of Luc than $\mathrm{Cu}$ NPs. Overall, it was apparent that $\mathrm{Cu}$ and $\mathrm{B}_{4} \mathrm{C}$ NPs disturbed the secondary structure of Luc, and the degree of disturbance increased as the concentration of NPs increased. 
A
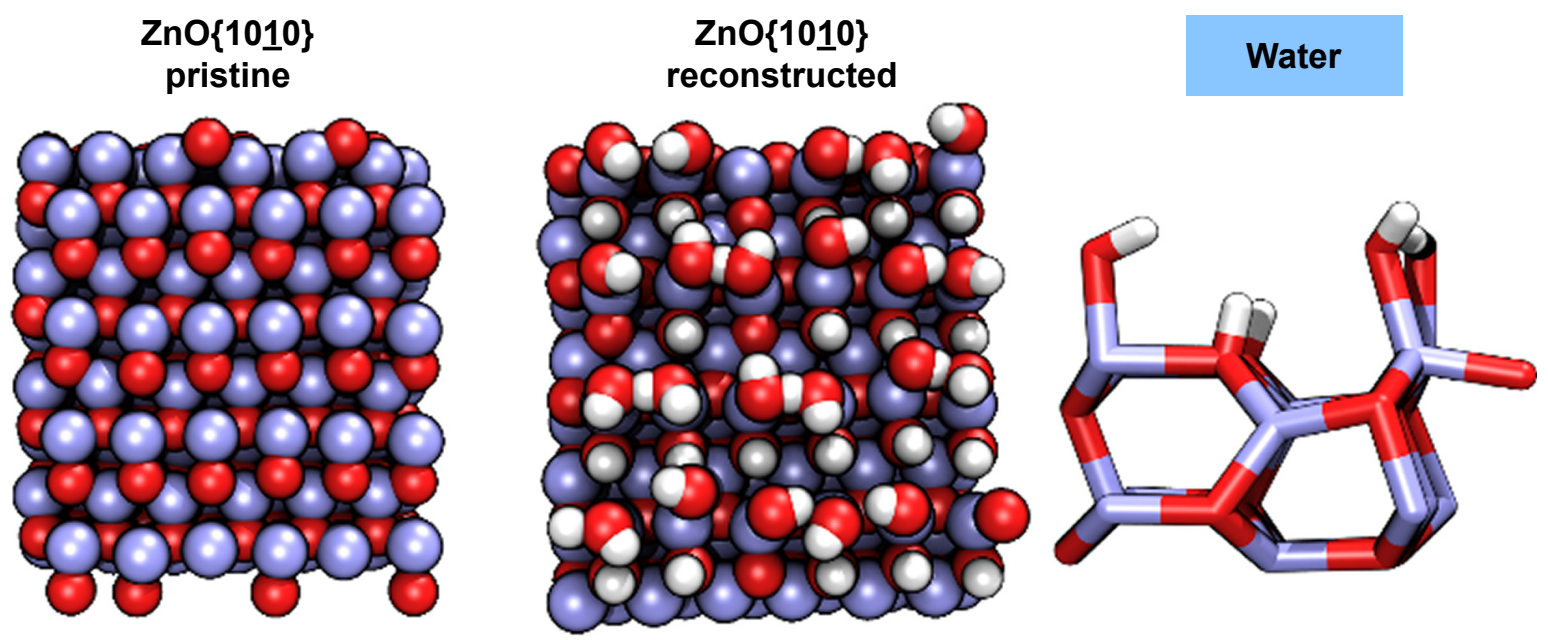

B
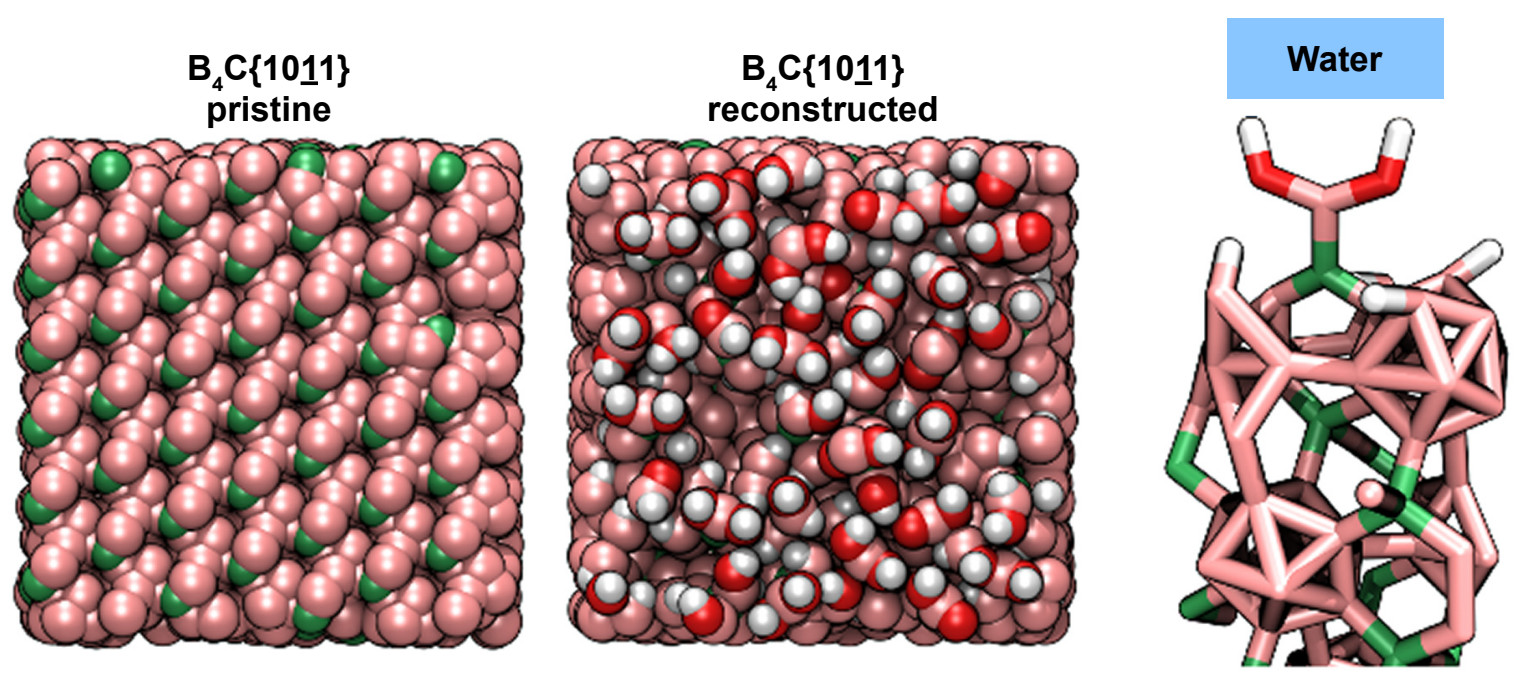

C
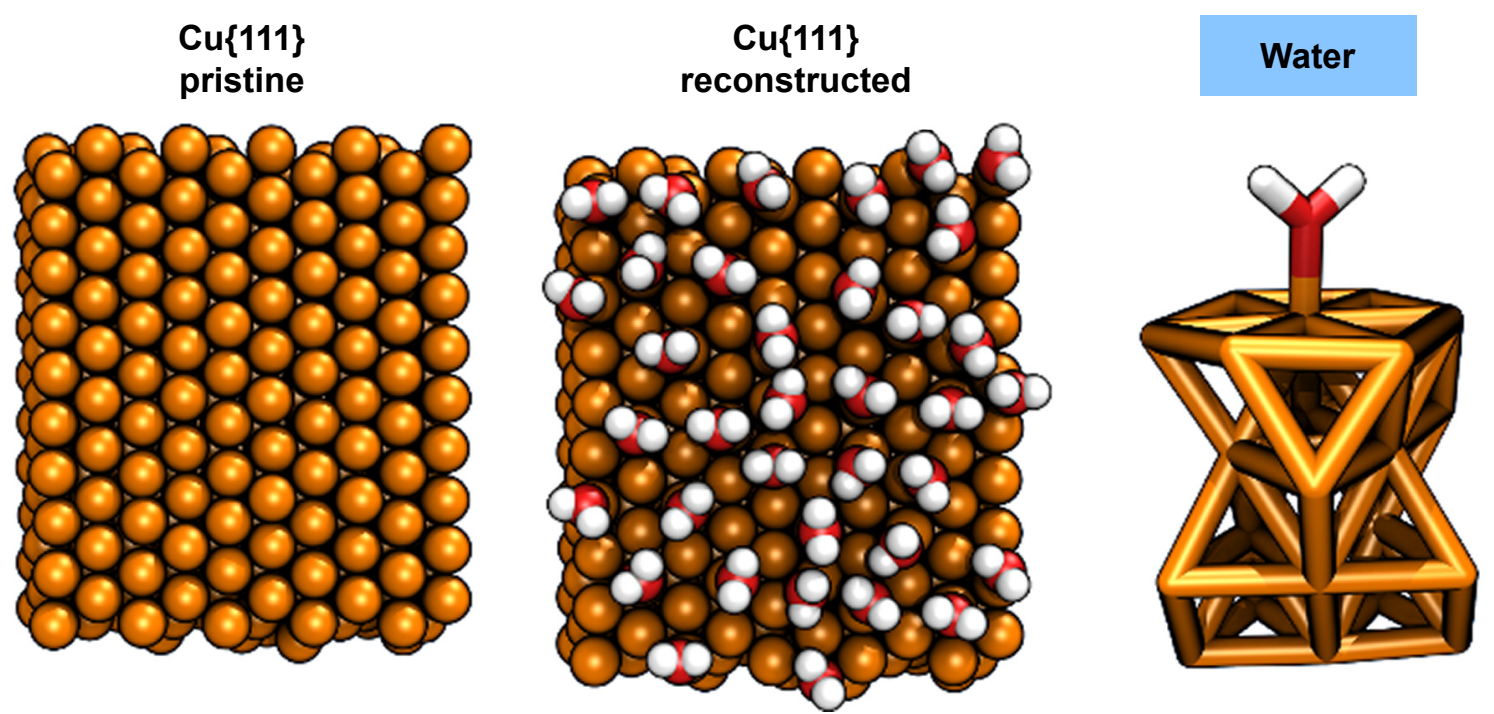

Figure 5 Reconstruction of pristine nanomaterial surfaces in the presence of water using reactive molecular dynamics simulations. The images on the left show a top-down view of the surface after equilibration in vacuum, while the images on the right show the same surfaces after I ns of reactive molecular dynamics in contact with water. The images on the right are side views of a select portion of the surface, revealing the bonding topology of the chemical modifications. The location of the aqueous phase above the surface is indicated. (A) The $\mathrm{ZnO}\{1010\}$ surface becomes almost completely populated by zinc hydroxides. (B) The $\mathrm{B}_{4} \mathrm{C}\{1011\}$ surface forms boronic acid groups as well as borane moieties. (C) The $\mathrm{Cu}\{\mathrm{III}\}$ surface accumulates some chemisorbed water molecules, but many under-coordinated $\mathrm{Cu}$ atoms remain exposed. 

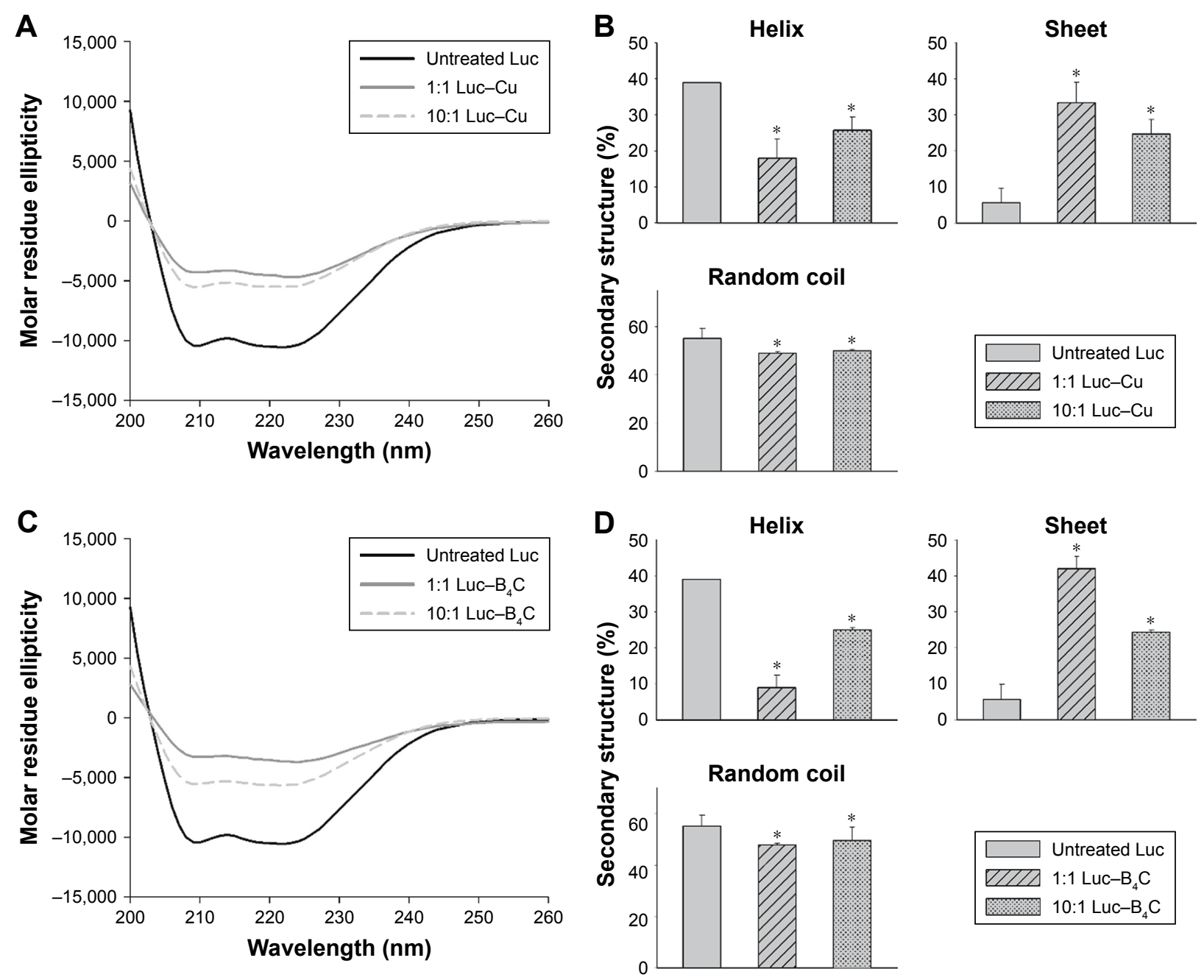

Figure 6 (A) CD spectra of Luc-Cu mixtures with I:I and I0:I ratios. (B) Distribution of secondary structure estimated by the K2D algorithm provided by DichroWeb.42-44 (C) $C D$ spectra of Luc- $\mathrm{B}_{4} C$ mixtures with I:I and I0:I ratios. (D) Distribution of the secondary structures. Untreated (native) Luc was used as a control. *Significant difference between untreated Luc and Luc-NP mixtures $(n=6, P<0.05)$.

Abbreviations: $C D$, circular dichroism; Luc, luciferase; NP, nanoparticle.

Taken together, the $\mathrm{CD}$ data suggest that $\mathrm{Cu}$ and $\mathrm{B}_{4} \mathrm{C}$ NPs induce substantial structural rearrangement in the Luc protein. These data are consistent with the prior fluorescence and luminescence measurements. Although the biophysical or biochemical impact of the nano-bio interaction was the driving force behind this investigation, the NP series were tested by MTT assay on NIH3T3 cells. The $\mathrm{B}_{4} \mathrm{C} \mathrm{NPs} \mathrm{absorb}$ in the $562 \mathrm{~nm}$ range, interfering with this assay. The cell viability of the remaining NPs had the following ranking: $\mathrm{MgO}>\mathrm{Fe}_{2} \mathrm{O}_{3}>\mathrm{NiO}>\mathrm{ZnO}>\mathrm{Cu}$, where only $\mathrm{Cu}$ and to a lesser extent $\mathrm{NiO}$ and $\mathrm{ZnO}$ were significantly different than $\mathrm{MgO}, \mathrm{Fe}_{2} \mathrm{O}_{3}$ or controls. Given these data, the $\mathrm{NiO}$ and $\mathrm{ZnO}$ were compared to $\mathrm{MgO}$ in the mouse splenocyte assay, ${ }^{45}$ where only $\mathrm{NiO}$ significantly altered the $\mathrm{P} 1 / \mathrm{P} 2$ ratio after propidium iodide staining and flow cytometry analysis (data not shown).

\section{Conclusion}

In conclusion, here comparative functional nano-bio analysis was performed. A change in fluorescence intensity was observed in the presence of all NPs tested. The largest change in both these parameters was seen with $\mathrm{Cu}$ NPs and $\mathrm{B}_{4} \mathrm{CNPs}$. These NPs in particular also greatly impact the enzyme kinetics and bioluminescence output of the enzyme, with $\mathrm{Cu}$ NPs prolonging the kinetics and $\mathrm{B}_{4} \mathrm{C}$ NPs greatly inhibiting bioluminescence. Furthermore, trypsin digestion studies show that $\mathrm{B}_{4} \mathrm{CNPs}$ protect Luc from degradation, whereas the presence of $\mathrm{Cu}$ NPs increases the rate of degradation with virtually no intact enzyme remaining after only a short period of incubation. These data suggest that these two NPs in particular have very different conformational effects on the enzyme. The increase in UV absorbance seen in the presence of $\mathrm{Cu}$ NPs, as contrasted with all other NPs where sedimentation of the 
Luc bound NPs and loss of UV absorbance in the supernatant occurred, is also consistent with partial protein unfolding as a consequence of $\mathrm{Cu}-\mathrm{NP}$ interaction (Figure S3). Certainly cerium oxide and $\mathrm{ZnO}$ have similarly been shown to induce conformational changes on thermal denaturation when monitoring Trp fluorescence or UV absorbance changes to fibrinogen and albumin similarly. ${ }^{17}$ By contrast, the fine structure observed in the PL spectra in the presence of $\mathrm{Fe}_{2} \mathrm{O}_{3}$ NPs and the quantum efficiency energy change in the presence of $\mathrm{ZnO}$ NPs suggests that the mechanisms of these NP effects on enzymes may be more complicated and may involve interactions between the NPs and substrate (in this case, D-luciferin), which need to be further explored. Finally, the inhibition seen by $\mathrm{B}_{4} \mathrm{C}$ appears to be unique in comparison to the other NPs, where no bioluminescence was detected even though this NP protects against trypsin digestion and does appear to induce conformation change as seen by 2-D FDS and CD. In this case, no photoelectron disturbance or quantum efficiency change in the presence of substrate was seen. For the most part, the metal or metal oxide surfaces appear to behave similarly in water where enzyme interaction causes an increase in NP size and a decrease in $\mathrm{ZP}$ consistent with their protein association. However, here again, $\mathrm{B}_{4} \mathrm{C}$ behaves very differently and in this case the molecular dynamics simulations of its surface shed some insight suggesting that, in water, boron surfaces convert to boronic acid, which likely leads to hydrogenbonding interactions with protein. This is consistent with the ZP change. Whereas the ZP of all other materials shifted to the negative upon protein interaction, the $\mathrm{ZP}$ of $\mathrm{B}_{4} \mathrm{C}$ NPs shifted to the positive. Chromatographic interactions with amino acids, particularly with glutamate, were quite distinct between $\mathrm{B}_{4} \mathrm{C}$ and $\mathrm{Fe}_{2} \mathrm{O}_{3}$ again suggesting the fundamentally different physicochemical behavior of $\mathrm{B}_{4} \mathrm{C}$ versus the wellcharacterized $\mathrm{Fe}_{2} \mathrm{O}_{3}$ metal oxide NPs. These results suggest that this panel of NPs, particularly $\mathrm{B}_{4} \mathrm{C}$ and $\mathrm{Cu}$ as well as $\mathrm{Fe}_{2} \mathrm{O}_{3}$ $\mathrm{NP}$, should be further evaluated against disease-relevant ${ }^{10,18,39}$ and physiologically significant enzymes.

\section{Acknowledgments}

SET was supported by the Undergraduate Summer Research Fellowship (American Physiological Society) and RKD by a research grant from the National Cancer Institute (7R15CA139390-03). We would like to thank Miranda Hurst, Kate Inchun, Chandler Curtis and Dr Santosh Aryal for their help and suggestions with the manuscript and Dr Nancy A. Montiero-Riviere and the Nanotechnology Innovation Center of Kansas State (NICKS) for the availability of equipment and generous start up. We would also like to thank Baolin Wang and Amanda Hoffman who supported the cell culture experiment and absorbance background determinations. Our additional thanks go to the Molecular Biology Core funded by Kansas State University College of Veterinary Medicine for the use of the facility.

\section{Disclosure}

The authors report no conflicts of interest in this work.

\section{References}

1. Xia XR, Monteiro-Riviere NA, Riviere JE. An index for characterization of nanomaterials in biological systems. Nat Nanotechnol. 2010; 5(9):671-675.

2. Xu M, Li J, Iwai H, et al. Formation of nano-bio-complex as nanomaterials dispersed in a biological solution for understanding nanobiological interactions. Sci Rep. 2012;2:406.

3. Yu Y, Wang J, Liu J, Ling D, Xia J. Functional assembly of protein fragments induced by spatial confinement. PLoS One. 2015;10(4): e0122101.

4. Hsu CY, Chen CW, Yu HP, Lin YF, Lai PS. Bioluminescence resonance energy transfer using luciferase-immobilized quantum dots for self-illuminated photodynamic therapy. Biomaterials. 2013;34(4): 1204-1212.

5. Lim JH, Park GC, Lee SM, et al. Surface-tunable bioluminescence resonance energy transfer via geometry-controlled $\mathrm{ZnO}$ nanorod coordination. Small. 2015;11(28):3469-3475.

6. Foroozandeh P, Aziz AA. Merging worlds of nanomaterials and biological environment: factors governing protein corona formation on nanoparticles and its biological consequences. Nanoscale Res Lett. 2015;10:221.

7. Mariam J, Sivakami S, Dongre PM. Albumin corona on nanoparticles - a strategic approach in drug delivery. Drug Deliv. 2016;23(8): 2668-2676.

8. Moon SH, Choi WJ, Choi SW, et al. Anti-cancer activity of $\mathrm{ZnO}$ chips by sustained zinc ion release. Toxicol Rep. 2016;3:430-438.

9. Mishra PK, Mishra H, Ekielski A, Talegaonkar S, Vaidya B. Zinc oxide nanoparticles: a promising nanomaterial for biomedical applications. Drug Discov Today. 2017;22(12):1825-1834.

10. DeLong RK, Mitchell JA, Morris RT, et al. Enzyme and cancer cell selectivity of nanoparticles: inhibition of 3-D metastatic phenotype and experimental melanoma by zinc oxide. J Biomed Nanotechnol. 2017; 13(2):221-231.

11. Cha SH, Hong J, McGuffie M, Yeom B, VanEpps JS, Kotov NA. Shapedependent biomimetic inhibition of enzyme by nanoparticles and their antibacterial activity. ACS Nano. 2015;9(9):9097-9105.

12. Lin YG, Hsu YK, Chen SY, Lin YK, Chen LC, Chen KH. Nanostructured zinc oxide nanorods with copper nanoparticles as a microreformation catalyst. Angew Chem Int Ed Engl. 2009;48(41):7586-7590.

13. Nasseri MA, Kamali F, Zakerinas B. Catalytic activity of reusable nickel oxide nanoparticles in the synthesis of spirooxindoles. RSC Adv. 2015;5:26517-26520.

14. Ganguly A, Trinh P, Ramanujachary KV, Ahmad T, Mugweru A, Ganguli AK. Reverse micellar based synthesis of ultrafine MgO nanoparticles $(8-10 \mathrm{~nm})$ : characterization and catalytic properties. J Colloid Interface Sci. 2011;353(1):137-142.

15. Bhogale A, Patel N, Mariam J, Dongre PM, Miotello A, Kothari DC. Comprehensive studies on the interaction of copper nanoparticles with bovine serum albumin using various spectroscopies. Colloids Surf B Biointerfaces. 2014;113:276-284.

16. Bhogale A, Patel N, Sarpotdar P, et al. Systematic investigation on the interaction of bovine serum albumin with $\mathrm{ZnO}$ nanoparticles using fluorescence spectroscopy. Colloids Surf B Biointerfaces. 2013;102: 257-264. 
17. Simón-Vázquez R, Lozano-Fernández T, Peleteiro-Olmedo M, González-Fernández A. Conformational changes in human plasma proteins induced by metal oxide nanoparticles. Colloids Surf B Biointerfaces. 2014;113:198-206.

18. Gann H, Glaspell G, Garrad R, et al. Interaction of $\mathrm{MnO}$ and $\mathrm{ZnO}$ nanomaterials with biomedically important proteins and cells. J Biomed Nanotechnol. 2010;6(1):37-42.

19. Yang Q, Liang J, Han H. Probing the interaction of magnetic iron oxide nanoparticles with bovine serum albumin by spectroscopic techniques. J Phys Chem B. 2009;113(30):10454-10458.

20. Dembereldorj U, Ganbold EO, Seo JH, Lee SY, Yang SI, Joo SW. Conformational changes of proteins adsorbed onto $\mathrm{ZnO}$ nanoparticle surfaces investigated by concentration-dependent infrared spectroscopy. Vib Spectrosc. 2012;59:23-28.

21. Katzenstein GE, Vrona SA, Wechsler RJ, Steadman BL, Lewis RV, Middaugh CR. Role of conformational changes in the elution of proteins from reversed-phase HPLC columns. Proc Natl Acad Sci U S A. 1986; 83(12):4268-4272.

22. Ugarova NN, Brovko LY. Protein structure and bioluminescent spectra for firefly bioluminescence. Luminescence. 2002;17(5):321-330.

23. Conti E, Franks NP, Brick P. Crystal structure of firefly luciferase throws light on a superfamily of adenylate-forming enzymes. Structure. 1996;4(3):287-298.

24. Mortazavi M, Hosseinkhani S. Design of thermostable luciferases through arginine saturation in solvent-exposed loops. Protein Eng Des Sel. 2011;24(12):893-903.

25. Branchini BR, Southworth TL, Murtiashaw MH, Boije H, Fleet SE. A mutagenesis study of the putative luciferin binding site residues of firefly luciferase. Biochemistry. 2003;42(35):10429-10436.

26. Branchini BR, Magyar RA, Murtiashaw MH, Portier NC. The role of active site residue arginine 218 in firefly luciferase bioluminescence. Biochemistry. 2001;40(8):24102418.

27. Dementieva EI, Fedorchuk EA, Brovko LY, Savitskii AP, Ugarova NN. Fluorescent properties of firefly luciferases and their complexes with luciferin. Biosci Rep. 2000;20(1):21-30.

28. Amini-Bayat Z, Hosseinkhani S, Jafari R, Khajeh K. Relationship between stability and flexibility in the most flexible region of Photinus pyralis luciferase. Biochim Biophys Acta. 2012;1824(2):350-358.

29. Voeikov VL, Yablonskaya OI. Stabilizing effects of hydrated fullerenes $\mathrm{C}_{60}$ in a wide range of concentrations on luciferase, alkaline phosphatase, and peroxidase in vitro. Electromagn Biol Med. 2015;34(2): $160-166$.

30. Barber S, Abdelhakiem M, Ghosh K, et al. Effects of nanomaterials on luciferase with significant protection and increased enzyme activity observed for zinc oxide nanomaterials. J Nanosci Nanotechnol. 2011; 11(12):10309-10319.

31. Chakraborti S, Chatterjee T, Joshi P, et al. Structure and activity of lysozyme on binding to $\mathrm{ZnO}$ nanoparticles. Langmuir. 2010;26(5): 3506-3513.
32. Käkinen A, Ding F, Chen P, Mortimer M, Kahru A, Ke PC. Interaction of firefly luciferase and silver nanoparticles and its impact on enzyme activity. Nanotechnology. 2013;24(34):345101.

33. Alam R, Karam LM, Doane TL, et al. Near infrared bioluminescence resonance energy transfer from firefly luciferase - quantum dot bionanoconjugates. Nanotechnology. 2014;25(49):495606.

34. Lim JH, Park GC, Lee SM, et al. Surface-tunable bioluminescence resonance energy transfer via geometry-controlled $\mathrm{ZnO}$ nanorod coordination. Small. 2015;11(28):3469-3475.

35. Vasquez ES, Feugang JM, Willard ST, Ryan PL, Walters KB. Bioluminescent magnetic nanoparticles as potential imaging agents for mammalian spermatozoa. J Nanobiotechnology. 2016;14:20.

36. Delong RK, Hurst MN, Aryal S, Inchun NK. Unique boron carbide nanoparticle nanobio interface: effects on protein-RNA interactions and 3-D spheroid metastatic phenotype. Anticancer Res. 2016;36(5):2097-2103.

37. Ghisaidoobe $A B$, Chung SJ. Intrinsic tryptophan fluorescence in the detection and analysis of proteins: a focus on Förster resonance energy transfer techniques. Int J Mol Sci. 2014;15(12):22518-22538.

38. Tsonev LI, Hirsh AG. Fluorescence ratio intrinsic basis states analysis: a novel approach to monitor and analyze protein unfolding by fluorescence. J Biochem Biophys Methods. 2000;45(1):1-21.

39. Hurst MN, DeLong RK. Two-dimensional fluorescence difference spectroscopy to characterize nanoparticles and their interactions. Sci Rep. 2016;6:33287.

40. Fannes T, Vandermarliere E, Schietgat L, Degroeve S, Martens L, Ramon J. Predicting tryptic cleavage from proteomics data using decision tree ensembles. J Proteome Res. 2013;12(5):2253-2259.

41. Sali A, Blundell TL. Comparative protein modelling by satisfaction of spatial restraints. J Mol Biol. 1993;234(3):779-815.

42. Lobley A, Whitmore L, Wallace BA. DICHROWEB: an interactive website for the analysis of protein secondary structure from circular dichroism spectra. Bioinformatics. 2002;18(1):211-212.

43. Whitmore L, Wallace BA. DICHROWEB, an online server for protein secondary structure analyses from circular dichroism spectroscopic data. Nucleic Acids Res. 2004;32:W668-W673.

44. Whitmore L, Wallace BA. Protein secondary structure analyses from circular dichroism spectroscopy: methods and reference databases. Biopolymers. 2008;89(5):392-400.

45. Medberry P, Dennis S, Van Hecke T, DeLong RK. pDNA bioparticles: comparative heterogeneity, surface, binding, and activity analyses. Biochem Biophys Res Commun. 2004;319(2):426-432.

46. Branchini BR, Magyar RA, Murtiashaw MH, Anderson SM, Helgerson LC, Zimmer M. Site-directed mutagenesis of firefly luciferase active site amino acids: a proposed model for bioluminescence color. Biochemistry. 1999;38(40):13223-13230. 


\section{Supplementary materials}

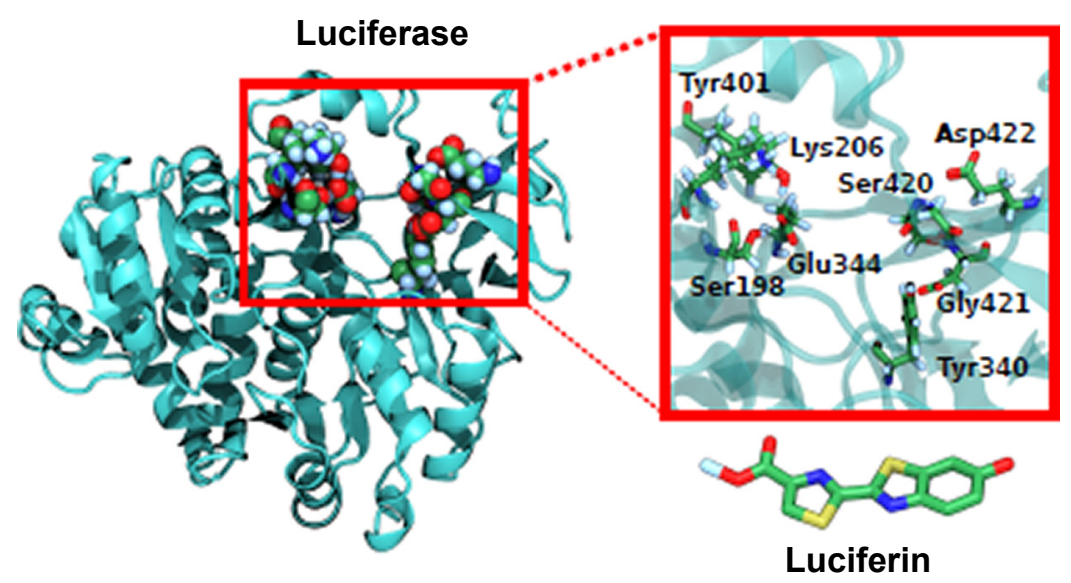

Figure SI Luc active site showing the luciferin substrate binding site.

Abbreviations: Luc, luciferase; Glu, glutamate; Tyr, tyrosine; Ser, serine; Lys, lysine; Asp, aspartate.

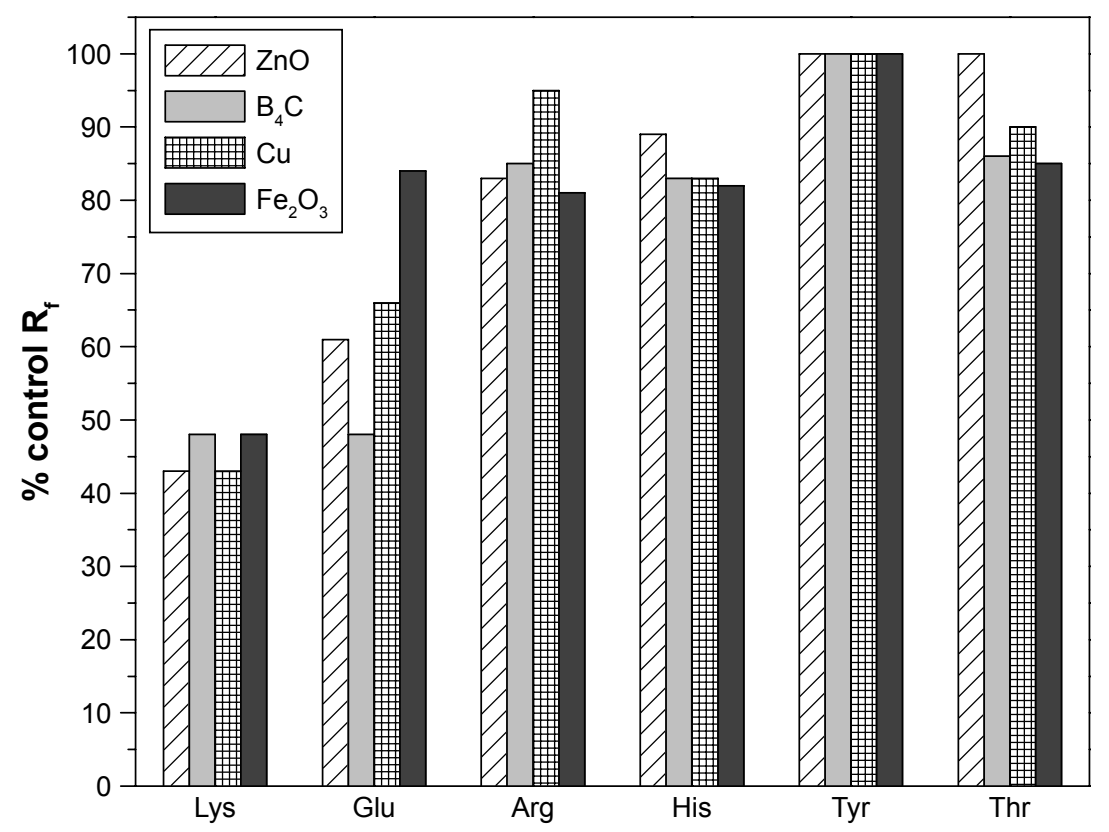

Figure S2 TLC migration of amino acids and the change in migration distance relative to the solvent front $\left(R_{f}\right)$ in the presence of each NP.

Abbreviations: TLC, thin layer chromatography; NP, nanoparticle; Lys, lysine; Glu, glutamate; Arg, arginine; His, histidine; Tyr, tyrosine; Thr, threonine. 


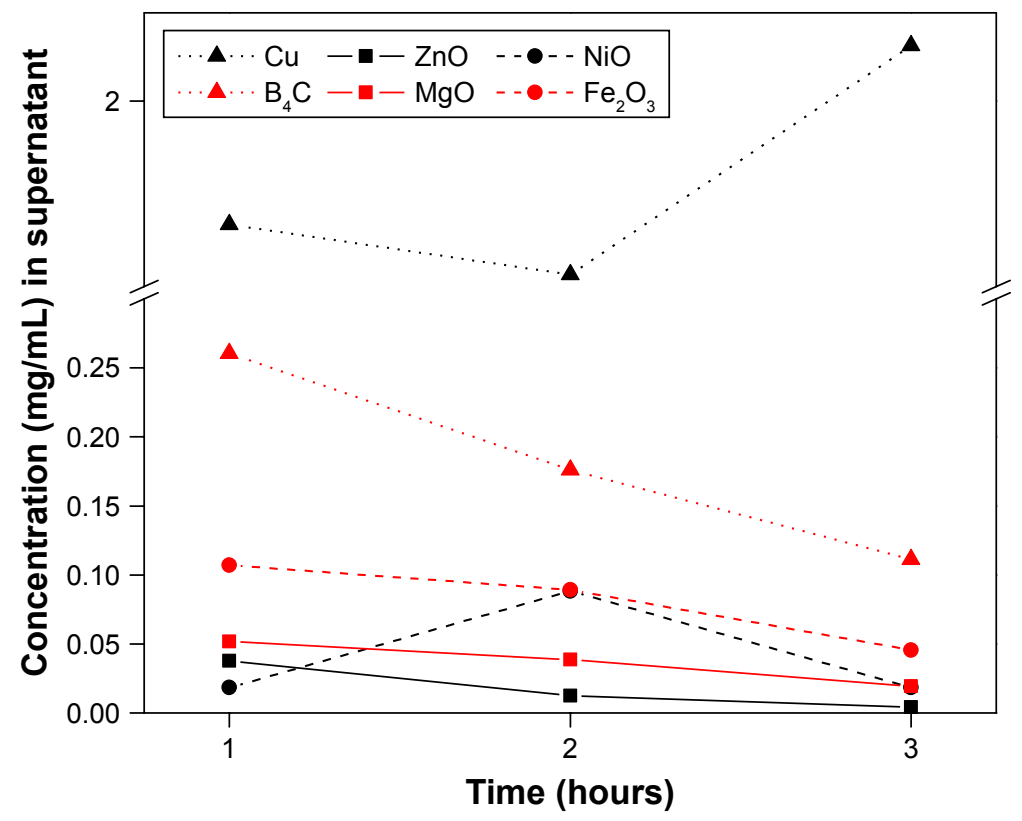

Figure S3 Binding capacity of Luc to NP surface. Cu NPs cause conformational changes leading to higher OD reading, and subsequently concentration in the supernatant. Abbreviations: Luc, luciferase; NPs, nanoparticles.

\section{Publish your work in this journal}

The International Journal of Nanomedicine is an international, peerreviewed journal focusing on the application of nanotechnology in diagnostics, therapeutics, and drug delivery systems throughout the biomedical field. This journal is indexed on PubMed Central, MedLine, CAS, SciSearch ${ }^{\circledR}$, Current Contents ${ }^{\circledR} /$ Clinical Medicine,
Journal Citation Reports/Science Edition, EMBase, Scopus and the Elsevier Bibliographic databases. The manuscript management system is completely online and includes a very quick and fair peer-review system, which is all easy to use. Visit http://www.dovepress.com/ testimonials.php to read real quotes from published authors. 